WellBeing International

WBI Studies Repository

1986

\title{
Socialized vs. Unsocialized Wolves (Canis lupus) in Experimental Research
}

\author{
Harry Frank \\ University of Michigan - Flint \\ Linda M. Hasselbach \\ University of Michigan - Flint \\ Dawn M. Littleton \\ Canisius College
}

Follow this and additional works at: https://www.wellbeingintlstudiesrepository.org/acwp_arte

Part of the Animal Experimentation and Research Commons, Animal Studies Commons, and the Other Psychiatry and Psychology Commons

\section{Recommended Citation}

Frank, H., Hasselbach, L.M., \& Littleton, D.M. (1986). Socialized vs. unsocialized wolves (Canis lupus) in experimental research. In M.W. Fox \& L.D. Mickley (Eds.), Advances in animal welfare science 1986/87 (pp. 33-49). Washington, DC: The Humane Society of the United States.

This material is brought to you for free and open access by WellBeing International. It has been accepted for inclusion by an authorized administrator of the WBI Studies Repository. For more information, please contact wbisr-info@wellbeingintl.org.

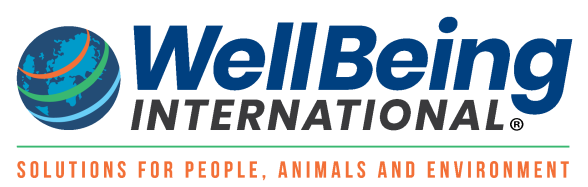




\title{
SOCIALIZED VS. UNSOCHALIZED WOLVES (CANIS LUPUS) IN EXPERIMENTAL RESEARCH ${ }^{1}$
}

\author{
Harry Frank ${ }^{2,5}$, Linda M. Hasselbach ${ }^{3}$, and Dawn M. Littletom ${ }^{4}$
}

The antiquity of man's interest in wild animal behavior is documented in upper Paleolithic cave drawings, which faithfully depict not only the color and form of the animals he hunted, but also their gait, posture, and social expression. Indeed, Geist (1978) suggests that man's capacity to survive the decline of Pleistocene megafauna was largely dependent on his ability to record and predict patterns of game migration and adapt his weaponry to changing predator-defense behaviors. With the rise of systematic agriculture, animal behavior occupied a less central role in human affairs, but remained a topic of continued fascination. Much of Aristotle's Biological Treatises, for example, is devoted to topics familiar to any contemporary student of behavioral biology: locomotion, reproduction, behavioral organization, and so forth.

In this century, the maturation of the behavioral sciences and the rise of environmental awareness have elevated the study of animal behavior to a professional discipline and have catapulted animal behavior researchers into the ranks of Nobel Laureates. Until recently, however, animal behavior research, whether conducted in the wild or in large, natural-setting enclosures, has been essentially an observational enterprise. Only in the last few decades have the precision and control of experimental methodology been brought to bear on the behavior of wild species (e.g., Leyhausen 1979).

Even in the arena of observational research, the question of whether or not one can draw legitimate inferences about wild animals from the behavior of tame specimens is not new, and among those who work with the gray wolf (Canis lupus) debate remains lively. Those who advocate use of unsocialized animals argue that cross-species social attachments may create behavioral abnormalities, and those who take the opposing view argue that socialization reduces stress and permits greater expression of natural behavior patterns.

In the experimental setting human contact is both more frequent and more intimate than in observational research, and the issue therefore assumes even greater importance. The present paper discusses two experimental studies of wolf information processing, one of which was conducted with unsocialized animals and one of which was conducted with socialized animals, 
and examines the both the management and methodological consequences of these approaches.

In 1980 the first author advanced a model of wolf and dog information processing suggesting that natural selection has favored evolution in the gray wolf (Canis lupus) of two concurrent systems of information processing. The more recently acquired system was characterized as "cognitive" and was suggested to have evolved in response to pressures that accompanied the rise of group hunting and that are relaxed under conditions of domestication. Accordingly, it was hypothesized that wolves should perform better than domestic dogs (Canis familiaris) on experimental problem-solving tasks, which call into play such complex cognitive capacities as insight into meansends relationships, serial organization of behavior, cognitive mapping, imagery, and foresight. The more primitive "instinctual" system was characterized as a repertoire of closed behavioral programs governing behaviors that (1) exhibit little plasticity and (2) are elicited by very specific stimulus configurations. In contrast, the model pointed out that domestic dogs have been selected (incidentally or intentionally) for tractability, that is, (1) behavioral plasticity, which is reflected in high behavioral variability, and (2) responsiveness to a broad range of stimuli. It was therefore hypothesized that domestic dogs should perform better than wolves on experimental training tasks, in which to-be-learned behaviors are typically acquired by some variant of operant conditioning.

In a series of studies conducted in 1980 and 1981, Frank and Frank (1982, $1983,1984,1985)$ administered an age-graded series of learning tasks to four Eastern timber wolf (C.ll lycaon) pups and four Alaskan Malamute ( $C$. familiaris) pups. Performance of the wolf pups was also compared with data reported by J.P. Scott, J.H. Fuller, and their associates (e.g., Scott and Fuller 1965; Scott et al. 1967) for large samples of domestic dogs. Training tasks were distinguished from problem-solving tasks on the basis of three criteria: (1) Cues were arbitrarily selected by the experimenter; (2) reinforcement was administered by the experimenter; (3) the to-be-learned behavior had no perceptible, functional connection with the reinforcement. As predicted, wolves performed better than dogs on seven of seven problem-solving measures, and dogs performed better than wolves on five of seven measures of training-task performance.

In presenting a summary of these results at a European mammalogy conference, Frank and Frank (1984) reported that by six weeks of age it was evident that the wolf pups had been only partially socialized to humans and that by 20 weeks of age were nearly as wary of the experimenters as pups reared without human contact. One of the conference participants (M. KileyWorthington, personal communication, August 1982) suggested that the wolf pups' relatively poor training-task performance might reflect differences in socialization, rather than differences in trainability. Basically, she argued that the problem-solving and training tasks differed not only in the informationprocessing capacities they tapped, but also in social context. By definition, the training tasks required that environmental feedback be mediated by a 
human training agent. In contrast, feedback in the problem-solving tasks resulted directly from the animals' transactions with the test apparatus. Insofar as socialization to humans might involve sensitization to human behavioral cues, therefore, the incompletely socialized wolf pups may have been operating at a comparative disadvantage in the training situation, much like a nearsighted child trying to learn to read.

To eliminate this possible source of confounding, the present authors repeated the training-task experiments in 1983 using an intensively socialized group of wolf pups. Except for the two measures in which the test hypotheses failed in the initial study, the 1983 study replicated the original results. Nevertheless, behavioral differences between our maternally reared (1980) and hand-reared (1983) wolf pups were profound-and in many ways much more instructive than their formal, quantitative similarities in test performance.

\section{Rearing Regimens}

1980. - The four pups used in the initial study, one male and one female from each of two litters, were acquired at 11 days ( $\pm 24 \mathrm{~h}$ ) of age from the Carlos Avery Game Park, Forest Lake, Minnesota. They were fostered on a highly socialized, mature maiden wolf approximately 67 days after ovulation. To promote lactation and maternal behavior, the foster mother was administered a series of progesterone injections beginning 10 days before the pups were introduced. Pups and foster mother were housed in $1.8 \times 1.2 \mathrm{~m}$ den-box inside a $3.7 \times 5.8 \mathrm{~m}$ barn. The barn and a $3.7 \times 1.5 \mathrm{~m}$ outdoor pen were erected on a single $3.7 \times 7.2 \mathrm{~m}$ concrete slab.

E. Klinghammer (personal communication, May 1980) had advised the experimenters that it is difficult to socialize wolf pups who interact with adult wolves, so a rather complicated routine was established by which two pups were with the experimenters at all times until approximately six weeks of age. Pairs were exchanged with the foster mother at mealtimes, and sleeping schedules were rotated and staggered (1) so that each pup spent one night with each experimenter followed by two nights with the foster mother and (2) so that no two pups spent consecutive nights together. When sleeping with an experimenter, pups were confined to an $1.2 \times 2 \mathrm{~m}$ plywood pen furnished only with a mattress. By six weeks of age, individual differences in socialization were apparent, so from six to nine weeks of age only the less socialized pups slept with the experimenters. At nine weeks of age the overnight socialization periods were discontinued, and contact hours were reduced to approximately six per day plus the time spent in the testing situation.

Although the foster mother lactated for seven weeks, production was minimal, and the pups were hand fed four times a day until four weeks of age. Solid food was introduced at three weeks of age, and the transition from a milk-replacer formula to a meat and kibble diet was complete by Day 38 , though nonnutritive suckling on the foster mother persisted for a short time thereafter. 
After six weeks of age, when experimental testing began, the pups were allowed occasional forays into the half-acre wooded enclosure which surrounded both the home barn and the $9.8 \times 9.8 \mathrm{~m}$ plywood testing arena. During these sessions they interacted freely with two adult male canids, an Alaskan Malamute and a Malamute-wolf hybrid, who were maintained in the same enclosure.

At 10 months of age the four pups were returned by air to the Carlos Avery Game Park.

1983. - The wolf pups used in the 1983 replication study were five males and three females acquired at 8 days $( \pm 12 \mathrm{~h})$ of age from the Ross Park Zoo, Binghamton, NY. Two adult females tended the pups from birth until six days of age, when the pups were removed from the den by the zoo staff, so it is uncertain whether they represent two litters or just one. It is known that at least three died shortly after birth, and 11 is an unusually large number for one litter. However, only one of the two females lactated, and she is known to have given birth to 13 pups in a single litter.

These pups were housed in a $3 \times 4 \mathrm{~m}$ air-conditioned laboratory at the University of Connecticut's Biobehavioral Sciences complex from nine days of age to 47 days of age, when construction was completed on our testing facility at the Spring Manor Poultry Farm (Mansfield Depot, CT). Their new accommodations included a $20 \times 22 \mathrm{~m}$ outdoor pen and an indoor kennel area (two $3.3 \times 3.3 \mathrm{~m}$ kennels and a $3.3 \times 6.6 \mathrm{~m}$ switching run) that occupied one end of a renovated $22 \times 6.3 \mathrm{~m}$ chicken coop. Most of the remaining floor space was given over to testing apparatus.

For the first three weeks the pups were bottle fed six times daily (midnight, 4:00 a.m., 8:00 a.m., noon, 4:00 p.m., and 8:00 p.m.). To facilitate the 4:00 a.m. feeding and to ensure virtual round-the-clock human contact, one of the authors slept in the lab next to the $1 \times 1 \mathrm{~m}$ monkey cage in which the pups were confined from approximately 1:00 a.m. to 7:30 a.m. At three weeks of age the 4:00 a.m. feeding was discontinued and the pups were left alone during the night. By this age they were too large to confine in the monkey cage for extended periods and were therefore allowed overnight run of the laboratory. Ten days later (Day 31) solid food was introduced, and within a day or two the pups had established themselves on a six-hour feeding cycle. All bottle feeding was discontinued at 39 days of age, though formula was provided in pans until the pups were 47 days old. At 50 days of age the number of daily feedings was reduced to three, at 75 days of age to two, and at 123 days to one.

Since the independent variable in our study was degree of socialization, the pups were not allowed contact with any canids until 6 weeks of age, and every effort was made to maximize their exposure to people. From their first day at the University of Connecticut, therefore, the pups were handled, cuddled, fed, romped with and petted by a host of volunteers from the university community and their families. Faculty members, graduate students, secretaries, friends of the project personnel, and children all served as surrogate packmates. Peak contact hours were during daytime feedings, especially noon 
and 4:00 p.m., but it was not unusual for project personnel to find themselves supervising visitors at 8:00 a.m. or 10:00 p.m. After the pups were transferred to the off-campus testing site, daytime visitation was confined to weekends, but security guards from the nearby Mansfield Training Center were frequent nocturnal visitors.

Because the University of Connecticut maintains a large population of both wild and domestic canids, stringent health precautions were observed until the pups received their first series of routine immunizations. Project personnel maintained a complete change of clothing at the laboratory, which left the building only to be laundered. Exposed skin areas were washed with a laboratory scrub compound before handling pups. Volunteers were required to bring clothing that had been machine washed and immediately sealed in plastic bags. In addition, all volunteers wore laboratory coats that were laundered with chlorine bleach and transported to and from the laboratory sealed in plastic bags. No outside footwear was permitted in the animal room. Volunteers and project personnel wore either socks laundered in chlorine bleach or rubber sandals that were immersed in a dilute solution of bleach (30:1) several times a day. Even visitors who did not handle the pups were required to wear laboratory coats and observe the same footwear procedures as the project staff and volunteers. Despite these precaurions, three of the eight contracted Corona's Virus (diagnosed by electron microscopy) at 17 days of age and required aggressive support (subcutaneous injections of Ringer's Lactate, dextrose intubation, anti-emetics, and antibiotics for secondary infection). The three survived the infection, but one of the others subsequently died of an intestinal blockage 10 days after swallowing the tip of a pacifier nipple.

At 7 months of age, the pups were donated to Wolf Haven in Tenino, WA.

\section{Differences}

From the animals' frame of reference, the most pervasive difference between the 1980 and 1983 studies was the 1983 pups' reduced susceptibility to stress resulting from human proximity. From the experimenter's frane of reference, the important differences lie in the behavioral conseguences of these differential stress levels, which often involve complex interactions and which may therefore be impossible to anticipate and difficult even to recognize without explicit, empirical comparison.

\section{Management and Maintenance}

In conducting research with sentient wild species, managenent and maintenance present problems that seldom arise in work with domesticated species. Many of these problems, however, can be eliminated or reduced if humans are accepted as a natural feature of their social environment. In addition to our colony of seven wolves, for example, the University of Connecticut also maintained a resident pack of unsocialized wolves. Because the resident pack's enclosure was an unpartitioned open field, their fear and aggressiveness made it impossible to perform even the most basic maintenance on a 
routine basis. In contrast, the present authors were able to disinfect the kennel area, remove feces, and inspect the fenceline daily and perform repairs or modifications on the physical plant as needed, complicated only by the wolves' obstreperous curiosity and the necessity of keeping unattended tools and equipment out of their reach. Other management differences had a more significant impact on our operation and merit discussion in greater detail.

Feeding. - The earliest notable differences between the 1980 and 1983 pups was in feeding behavior. The maternally reared (1980) litter were, from their first day out of the den, difficult to feed. While still on the bottle, any slight deviation in formula, stiffness or orifice opening of the nipple, temperature of the formula, position in which the pup was held, etc., was likely to result in rejection of the nipple. The only difficulty with the 1983 litter was obtaining nipples that were stiff enough to prevent the pups from aspirating formula in their enthusiasm.

We feel that the most plausible explanation for this difference surrounds the complex motivational components of feeding behavior. In the course of nursing, a pup satisfies hunger needs, receives tactile and thermal stimulation, and satisfies non-nutritive sucking needs. To the extent that all of these were satisfied by human caretakers in the 1983 litter, the bottle-feeding situation may have acquired secondary reinforcement value, in addition to the primary reinforcement associated with reduction of hunger. In the maternally reared 1980 litter, non-nutritive needs were largely satisfied by the foster mother wolf. The overall satisfaction derived from hand feeding may have been further reduced by the small but continuously available volume of milk produced by the foster mother. Alternatively, we also recognize the possibility that the stimulus pattern that elicits sucking behavior in wolf pups may have become more canalized in the 1980 pups, who nursed on their biological mothers until 11 days of age, than in the 1983 litter, who were removed from the den at 6 days of age.

After weaning, the feeding differences persisted. In order to ensure that the maternally reared pups ate anything, they were fed two at a time in individual dishes in the experimenter's home. They were fed three times a day from four weeks of age to nine weeks and twice a day until 15 weeks of age. Considerable time and effort were expended to overcome their indifference to food, which was seldom consumed in less than 45 minutes. After 20 weeks of age the pups were too unmanageable to be brought indoors and four rations were placed in different locations in the home barn. The hand-reared pups were, in comparison, almost insatiable. Indeed, they were so eager to eat that at five months of age it became necessary to confine them to their kennel at night so that the authors would not be mobbed when setting out their morning rations. Feedings seldom lasted longer than three to five minutes. At 20 days of age, when body weights were first recorded for both groups, the maternally reared pups averaged 3.9 pounds and the hand-reared pups 3.2 pounds. By 30 days of age both groups averaged 5.25 pounds, and the group averages remained essentially identical until 12 weeks of age. Although average weights for the two groups 
were thus very similar during the period of most rapid growth, the handreared pups came from smaller stock and may therefore have realized more of their growth potential. Furthermore, after 12 weeks of age the growth curve for the maternally reared pups flattened out, while the curve for the hand-reared pups continued to accelerate until they reached the capacity of the scale.

Health care.-The health care advantages of working with socialized wolves are discussed in detail by Albert, Goodmann and Klinghammer (in press) and by Klinghammer and Goodmann (in press). The explicit contrasts discussed below between health care delivery problems confronted with the maternally and hand-reared pups are not intended to pre-empt their recommendations, but, rather, to underscore them.

Injections were not really a problem with either group prior to two months of age. After their routine immunizations the 1980 litter had few health problems and therefore required no injections until health certificates were required for shipment to Minnesota when they were approximately 10 months old. Although the four pups were, by this time, confined to the home barn, the operation required more than an hour. One pup at a time was chivvied into the paddock and the guillotine door lowered. Then the first author cornered the pup and squeezed him against the fence fabric with his leg so the veterinarian could administer the injection from outside the pen. The author still bears prominent scars. The hand-reared (1983) pups received injections almost weekly from 17 days of age until seven months of age. Once the syringes were prepared, a typical round of booster shots for the entire group of seven required about 15 or 20 minutes. Pups were allowed into the testing area one at a time, and the delays were occasioned primarily by pups who had already received their shots crowding to get back in for additional attention.

Oral medications can be a much more difficult enterprise than injections. The usual procedure is to wrap pills in ground meat, cheese, or some other palatable carrier or to incorporate it into the animals' food (which should be attempted only after it is established that the medication does not produce a taste aversion). Liquid medication is injected into the mouth with a hypodermic syringe. For the 1980 pups, pills were always introduced in balls of canned cat food and, if accepted, subsequently mixed with their daily food. This, of course, was possible only so long as feeding was conducted individually and carefully monitored to ensure that every pup consumed his entire ration. Less palatable preparations were administered in liquid form, which often assumed the character of rodeo bulldogging. Group feeding made it impossible to incorporate medication into the 1983 pups' food, but they accepted unconcealed pills with good grace, even after we began daily heartworm prophylaxis, and liquid medication was received from a syringe with the same uncritical acceptance as bottle-fed formula. Indeed, especially palatable preparations (e.g., Strongid-T) were so eagerly consumed that we occasionally substituted such medications for food rewards administered during experimental testing. 
Body weights for both groups were recorded several times a week from 20 days of age until they exceeded the scale's capacity (30 pounds) at approximately 100 days of age. The 1980 pups, however, began to show fear of the scale at about four or five weeks, and keeping them on the weighing pan long enough to obtain an accurate reading simply became so stressful for both the pups and the experimenters that it was not always possible to obtain reliable recordings at every weighing. Since illness in a young pup is often reflected in body weight before other symptoms are manifest, the present authors contrived to make weighing a pleasurable activity for the 1983 pups. From three to seven weeks of age they were placed on the scale every two or three days and petted, stroked, and scratched until they either fell asleep or showed signs of wanting to leave. Within a week or two the pups would actively compete to occupy the weighing pan, and even after they became so heavy that the scale would tip over with a grating, metallic clatter when a pup tried to mount it, they showed no aversion to the scale. Weighing was discontinued only when the pups became too large to be completely supported by the pan. The pups in figures 1a-f range from 22 to 99 days of age. It should be noted that the 1980 pups were weighed far more often than the 1983 pups and therefore had more frequent exposure to the scale. The difference between the two groups' orientation to it must consequently be attributed to the positive reinforcement that human contact and attention constituted for the socialized pups.

The range of health care procedures endured by the 1983 litter was considerably greater than that experienced by the 1980 litter. In part, this was because the former were more tolerant, in part because they permitted (demanded, actually) more frequent intimate contact, thereby facilitating detection of health problems, and in part because the 1983 pups were reared in an environment that exposed them to more canine pathogens. Besides the medications mentioned above, several of the pups were treated for urinary tract conditions (Pseudomonas aeruginosa) and (Proteus sp.) for which vaginal and penile sheath lavages were prescribed. It is inconceivable that such a procedure would have been tolerated by the maternally reared pups, but the hand-reared pups accepted the treatment with absolute equanimity. The greatest test of their tolerance, however, came at 13 weeks of age. By this time their performance in perceptual tasks and difficulties negotiating new objects in their enclosure had led us to suspect that some of the pups might have juvenile cataracts, which is not uncommon in wolves weaned on commercial milk replacer before two weeks of age. The entire litter was therefore administered an ophthalmic examination by Dr. Herbert J. Van Kruiningen of the University's Pathobiology Department. Apart from the fact that Dr. Van Kruiningen was a total stranger to the pups, the examination required that they be manually restrained and an unfamiliar instrument be placed within a few inches from their eyes. The photograph in figure 2 (page 42) demonstrates the placidity with which this activity was accepted.

Logistics. - In addition to health care, one of the most difficult problems in working with wolves is logistics - getting the animals from one place to 

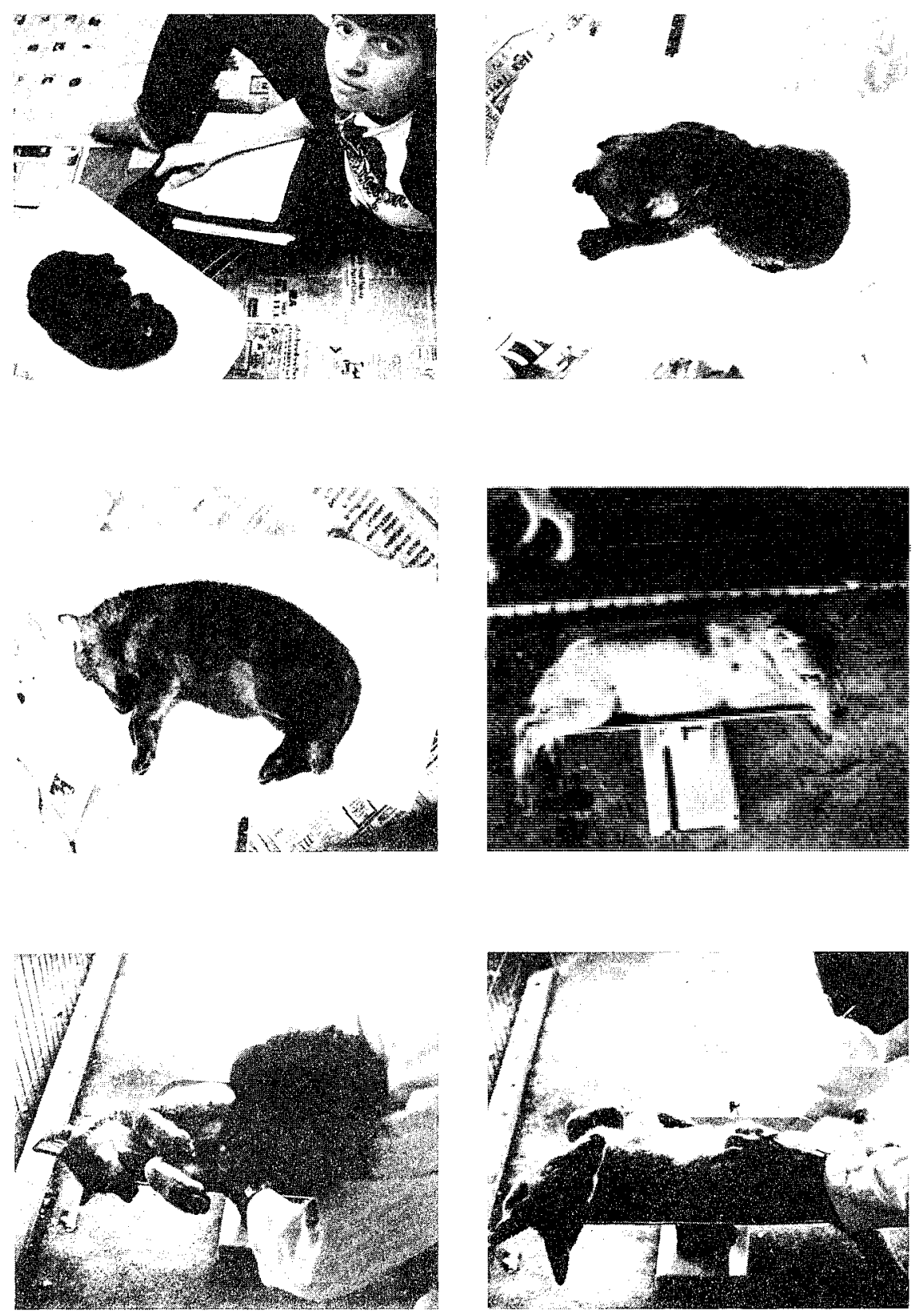

Figure 1a-f. Socialized wolf pups on baby scale from 22 to 99 days of age. 


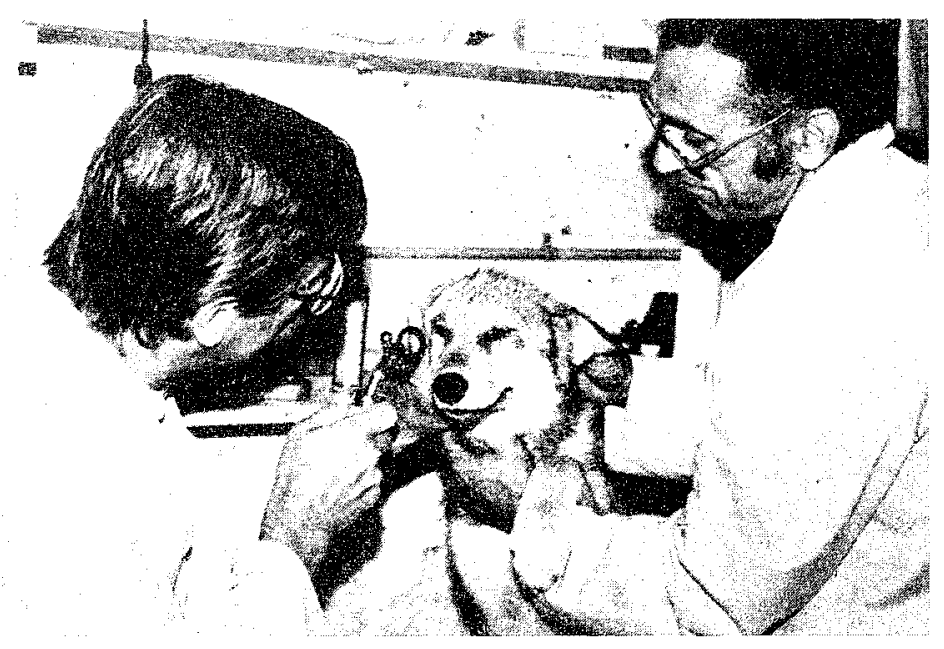

Figure 2. Socialized wolf pup undergoing ophthalmological examination.

another. Although the 1980 research site occupied a half-acre enclosure, the pups spent most of their first 20 weeks either in the experimenters' house or confined to their home barn. This management practice was necessitated by their speed, agility, and general reluctance either to return to the barn or to approach the experimenters. After a mid-morning release into the main compound, it frequently required an hour or more to round the pups up and return them to the barn so that we could proceed with afternoon testing. "Recapture" was often possible only with the aid of the foster mother wolf, who would chase down a wayward pup and jaw-pin it until one of the experimenters arrived. At 67 days of age one pup remained loose in the enclosure all night and was recovered the next morning when we put the Malamute and hybrid on leash, and she approached to greet them. By 119 days of age, it became necessary to restrict the pups' access to water during their romps in the enclosure and to use water to bait them back into the barn. After 130 days of age, the pups would avoid entering the barn if the experimenters were inside the enclosure, and it was necessary to rig lines to the paddock gate so that it could be shut by remote control during feeding. Within a few days, however, the pups adopted the strategy of feeding in shifts so that only one or two pups were in the paddock at any one time. Thereafter they were permanently confined to the barn until early November, just after the testing program was completed, when the foster mother worked the exterior latch on the barn door and released the pups. They remained at large for several weeks, and our efforts to recapture them are instructive.

First, new fencing was erected to connect the barn with the testing arena and the perimeter fence of the compound. This created an irregular quadrilateral enclosure (approximately $20 \times 20 \mathrm{~m}$ ) with a single, narrow entrance between the barn and the perimeter fence. A roll of 6 -foot welded wire 
fence fabric was secured to the barn, so that someone in the barn could - in principle-slip out, unroll the 6-m length of wire and fasten it to the fence, thus confining the pups in the small enclosure. For several days the pups were fed inside this enclosure, and on the first absolutely windless day one experimenter ensconced himself in the barn, from which he could watch the small enclosure through a knothole and rush out to unroll the wire as soon as all of the pups began to eat. The pups approached the barn warily, entering the small enclosure no more than two at a time and only for a few seconds. Eventually, the boldest male entered the enclosure alone and carried the four food dishes out one at a time.

The trap was finally sprung only by a most devious ploy. A ladder was placed against the outside of the perimeter fence at the entrance to the small enclosure. After several days one experimenter concealed himself in the woods some $200 \mathrm{~m}$ beyond the fence. The pups were fed in the small enclosure, and as soon as they began to eat, the other experimenter sounded a whistle, and the first experimenter approached the fence on cross-country skis, keeping the barn between himself and the pups. Skis are almost silent in deep snow, and he was able to reach the fenceline undetected, kick off the skis, climb the ladder, drop into the compound, unroll the wire and secure it.

All of this elaborate and time-consuming effort was in dramatic contrast to the procedures required to return the socialized, 1983 pups to their kennel-we called them.

In addition to the routine logistical demands involved in management of any animal colony, experimental research imposes other requirements. Animals must be moved to and from the testing site, placed in and removed from test apparatus, and in some cases kept isolated from others who have not yet been tested. In 1980 this was accomplished by first rounding up the entire group, confining them to the paddock, cornering the pup who was to be tested, carrying him to the test arena, and then carrying him back to the home barn after testing. These experimental logistics were particularly onerous with two of our tests.

At 15 weeks of age the pups were administered a visual discrimination (oddity) task using the Wisconsin General Test Apparatus (WGTA). The WGTA test chamber was a $1 \times 1 \mathrm{~m}$ box mounted on a 1 -m-high table. Pups entered and exited the chamber through a rear door. After testing, the 1980 pups generally refused to leave the chamber voluntarily, and it was necessary to reach in and extract them as gently as possible. This often produced panic, and one experimenter still carries a deciduous canine tooth embedded in his forearm.

In 1983 our only problem was holding back the mob of yet-untested pups and limiting admission to the testing area to a single participant. Once out of the kennel the testee was usually content to follow or precede the experimenter to the apparatus. Although these pups were, like their predecessors, sometimes reluctant to return to the compound when testing was complete, this was generally expressed in the form of submission and prolonged play solicitation, rather than defensive aggression. Figures $3 a$ and $3 \mathrm{~b}$ illustrate 
the procedures required to get the 1983 pups into and out of the test apparatus itself.
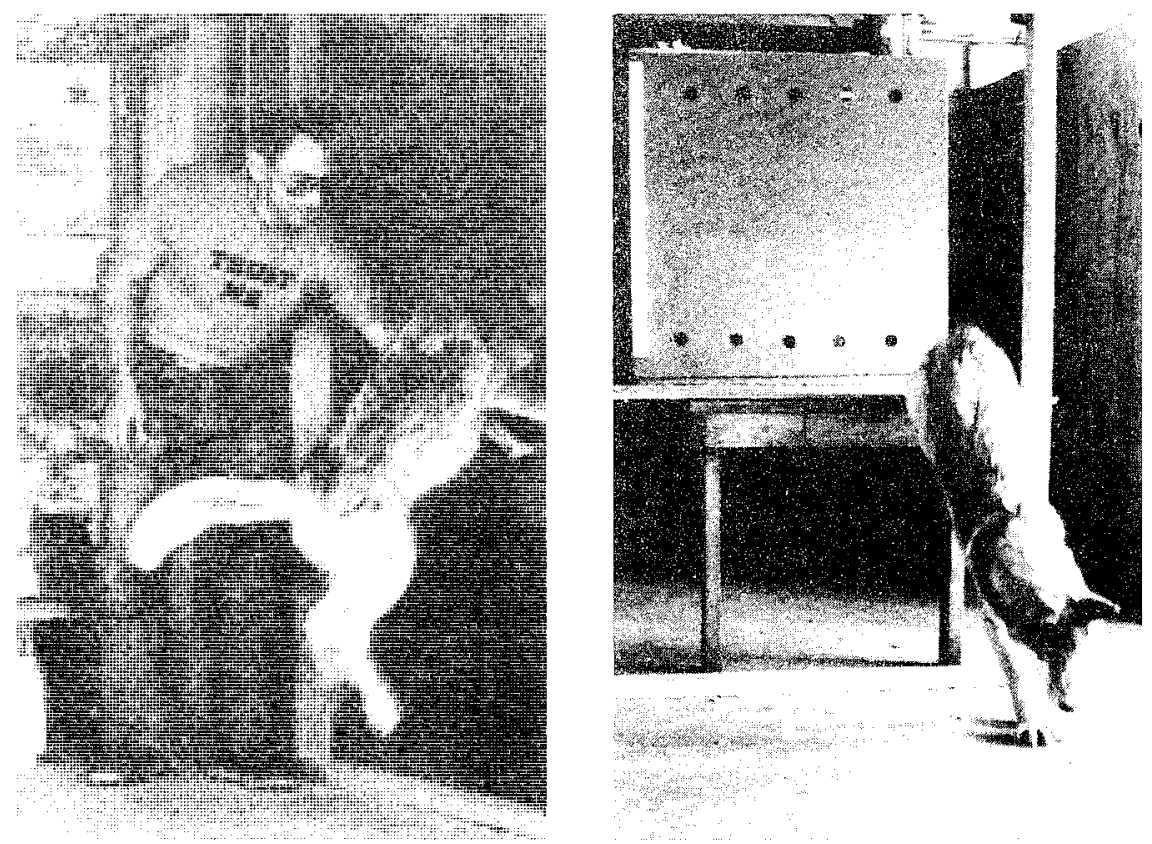

Figure 3. a. Socialized wolf enters testing chamber of Wisconsin General Test Apparatus on author's signal.

Figure 3. b. Socialized wolf leaves Wisconsin General Test Apparatus when called by author (not shown).

A test of intermodal (visual vs. auditory) cue discrimination was administered at 22 weeks of age and employed the WGTA test chamber as a start box, equipped for this experiment with a plexiglass guillotine door in front, through which pups were released into the runway of a T-maze. If an auditory signal (whistle) was presented just prior to release, one exit of the T would be found open; if a visual signal (a flashing light) was presented, the other exit would be found open. After each trial it was expected that the pup would return to the start box, receive fook reward for a correct choice, and begin the next trial. This procedure, which worked so well with Scott and Fuller's domestic dogs (1965, pp. 238-42), proved completely unworkable with the 1980 pups. As soon as a pup discovered the open exit he either bolted for the wall of the test arena and attempted to scramble over, or, more typically, simply did his best to avoid recapture, leading the experimenters on a frantic chase that might last several minutes. Small pens therefore had to be constucted outside each arm of the $T$, and pups had to be cartied from the pen to the stat box after each irial. 
Figures $4 \mathrm{a}$ and $4 \mathrm{~b}$ illustrate typical behavior of the 1983 pups in performing the cue-discrimination task. As with the visual discrimination (WGTA) task, our only problem was containment of those not scheduled for immediate testing. Because pups now weighed nearly 50 pounds, however, debarring all but one from the test area was more difficult than it had been at 15 weeks. On one occasion the stampede of volunteers bowled over the third author, and three pups managed to crowd into the start box sirnultaneously.
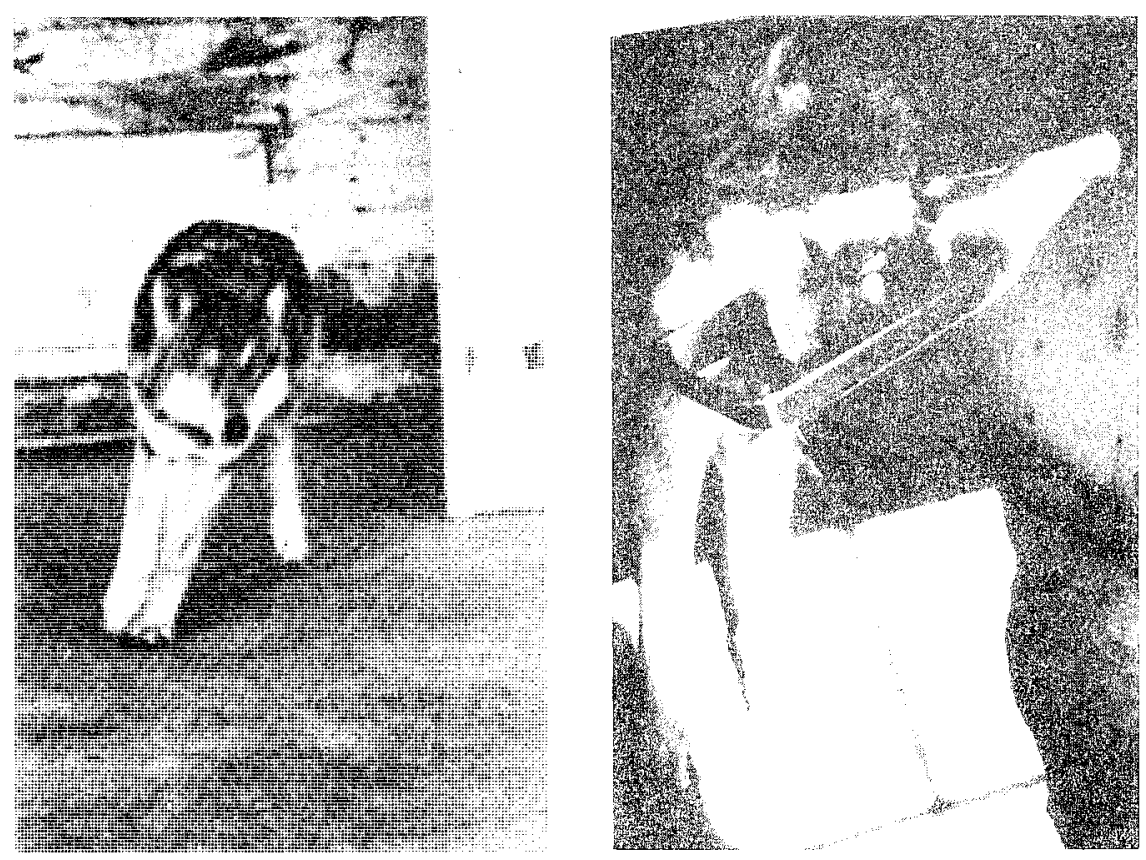

Figure 4a. Socialized wolf exits $T$-maze after correct choice and gallops back to start box. Figure 4 b. Socialized wolf returns to stat box and accepts food reward for correct response.

Transportation and shipping ate another logistical problem conf́ronting those who conduct research with wolves. When the 1980 wolves were shipped to Minnesota, they had to be immobilized with injections of ketamine hydrochloride and promazine $\mathrm{HCl}$ just to get them into their shipping kenthels. In transit to the airport and while awaiting departure, respiration and onder vital signs required continuous monitoring, and arrangenents were made with airport persomnel to keep the kennels in a quiet and relatively seciuded location until they could be stowed aboard the aircraft. The 1983 pups were administered a half-strengh dosage of oral acepromazine maleate several hours before flight time and were perfocty content to sit in the middle of 
a busy cargo bay at Bradley International Airport, with the doors to their kennels either closed or open, while the authors, cargo handlers, and casual passersby entertained them.

\section{Methodological Considerations: Error Variance and Confounding}

The design of any scientific experiment always requires the experimenter to balance costs of labor, equipment, and materiel against the quality and reliability of data. At some point, the cost of controlling extraneous variability almost inevitably exceeds the additional precision that such control confers. In our experience with socialized and unsocialized wolves, this trade-off does not arise. The comparative ease of managing socialized wolves not only reduces the overall expenditure of labor, but also the ratio of time spent in management activity to time spent in actual research activity. Furthermore, the use of socialized participants, far from "contaminating" data with "socialization artifacts," can reduce extraneous variation, both systematic (i.e., confounding) and random (i.e., error). Extraneous variability may arise from three major sources (plus interactions among the three): task variables, environmental variables, and subject variables.

Task variables. - Generally speaking, the easiest source of extraneous variability to control is that associated with the experimental task itself. This means not only that all participants must be presented the same puzzle, apparatus, or stimulus materials, but that all the experimental procedures must likewise be constant from participant to participant. In the 1980 study, circumstances that can be attributed to lack of socialization compelled the experimenters to introduce procedural deviations that might ordinarily be expected to increase error variance. At 10 weeks of age, the pups were administered a series of puzzle boxes that required performance of increasingly complex manipulations in order to extract a food dish:

Unfortunately, [the final day of testing] fell on July 4 , and testing was punctuated by a combination of intermittent thunder and neighborhood fireworks that distracted the first two [wolf pups] and convinced us to postpone testing the others until after the boliday weekend (Frank and Frank 1985, p. 269, emphasis added).

Thus, the last two wolf pups addressed the final and most complex problems after a two-day hiatus which the others did not experience. Such interruptions do not invariably influence performance but can in principle either enhance it by reducing satiation or diminish it by reducing the effects of continuous practice. Although testing in 1983 was also subject to such external auditory distractions as heavy truck traffic, unexpected visits by maintenance personnel and animal care inspectors, and the operation of nearby construction equipment, voice or touch of a familiar human was always sufficient to reassure the socialized pups and draw their attention back to the task at hand. Thus, Thus performance was never so disrupted that we considered postponement of testing or other departures from our standardized testing procedures. 
A similar deviation in our 1980 testing procedures occurred when one pup successfully escaped the test arena during the cue-discrimination test and remained at large for several days before she was recaptured and testing could resume. In 1983, our only logistical management problem involved pups breaking in to the test area, not breaking out.

Environmental variables. - Control of environmental variation that is unrelated to the experimental task itself is a more difficult and subtle problem. It is more difficult because the sources of variation can be almost infinite and may often be inherent in the research setting. For example, control of such factors as illumination, ambient temperature and windborne olfactory stimuli may simply be beyond the ability or economic resources of the experimenter. They are more subtle because they may interact with individual differences. In the example discussed above, the decision was made to postpone manipulation testing because it was felt that experimental deviation would introduce less error variance than the differential effects of auditory distraction on labile and phlegmatic individuals.

The most dramatic illustration of environmental lability in the 1980 pups was during visual discrimination on the WGTA. The experimenters had asked a colleague to photograph the session. To avoid distraction, the photographer used a telephoto lens from the upper story of the experimenters' house. Although she was $30 \mathrm{~m}$ from the test arena, concealed by a screened window and heavy curtains, the pups ignored the experimental task altogether and stared fixedly at the window until the photographer left. The socialization regimen imposed on the 1983 pups inured them to the presence of human strangers, and on occasion we were actually able to use unfamiliar personnel to assist with test administration.

Environmental stress interfered with test performance only once in 1983. One pup could not be habituated to isolation in the WGTA test chamber and tried relentlessly to dig, squeeze and chew his way out the moment he was confined. This problem would have been intractable with unsocialized pups, and we would have faced the choice of either eliminating his data or increasing error variance by recording refused attempts as failures. In the present instance, however, the pup relaxed and applied himself to the experimental task as soon as the third author climbed into the box and sat with him. (The author sat facing away from the stimulus clisplay to ensure that she neither cued nor reinforced correct responses.)

Subject variables. - Sources of performance variation that derive from individual differences are the least accessible and often the least tractable. Furthermore, as indicated above, temperament and personality factors can interact in complex and unpredictable ways with both task and environmental factors. In the present study, however, the most salient differences surround motivation and appear directly related to socialization.

In the 1980-81 study the only hypotheses that were not confirmed were the predictions that the Malamutes would perform better than the wolves on the visual discrimination (WGTA) and cue-discrimination (T-maze) tasks. In 
visual discrimination learning, wolf pups actually performed better than the Malamutes in the initial discrimination (though the differences were not statistically significant), but the dogs performed significantly better in reversal learning $(P \leqslant .025$; Frank and Frank 1984). Differences were in the expected direction on the T-maze but were only marginally significant $(P=.067$; Frank and Frank ibid.) and therefore equivocal. Food reinforcement was employed in both of these experiments, and the chronic indifference of the maternally reared (1980) pups toward food proffered at feeding time (never a problem with the perpetually greedy Malamutes) was also apparent in the testing situation. Food rewards were frequently ignored or consumed half-heartedly and often had to be offered in smorgasbord variety to maintain any overt interest whatsoever. In this connection, the latent learning experiments of the 1930s (e.g., Tolman and Honzik 1930) demonstrated that animals may acquire to-be-learned behaviors but not perform them until performance is reinforced, i.e., until motivated by adequate incentive. This consideration raises the possibility that the 1980 pups' relatively poor performance on the two discrimination tasks might have reflected insufficient motivation, rather than inability to learn. This interpretation gains plausibility when it is noted that the significant difference between wolves and Malamutes in reversal learning on the WGTA was largely attributable to the wolves' frequent nonperformance or perseverative choice of the same stimulus object trial after trial.

The gustatory enthusiasm of the hand-reared (1983) pups offered a clear opportunity to eliminate the possible confounding of motivational factors. Despite the 1983 pups' eager participation in the cue-discrimination task and avid consumption of food reward (see figures $4 \mathrm{a}$ and $4 \mathrm{~b}$ ), none of them reached criterion, thereby providing unambiguous support for the original hypothesis. Much to our surprise, however, they performed significantly better than either the Alaskan Malamutes $(P \leqslant .05)$ or the 1980 wolves $(P \leqslant$ .005 ) on the WGTA reversal learning task and significantly better than the Malamutes on the initial discrimination task $(P \leqslant .005)$. They likewise performed better than the 1980 wolves in the initial discrimination phase of the experiment $\left(\bar{X}_{1980}=82.50 ; \bar{X}_{1983}=44.1\right)$, but the difference was not significant due to the immense performance variability of the 1980 pups. This variability was inflated by two of the pups, who exhibited only mild interest in the task and hovered just below criterion until the last few days of testing.

Conceptual interpretation of these results is beyond the scope of this paper, but the methodological implications are clear: Performance differences between wolves and Malamutes in the 1980-81 study were confounded by motivational factors, viz. differential incentive value of food reward, which was eliminated in the 1983 study by the use of hand-reared wolves who were thoroughly socialized to humans and as readily motivated by food reinforcement as their domestic congeners.

\section{Acknowledgements}

The authors wish to thank the University of Connecticut School of Agriculture, which provided the testing site, the Pathobiology Department for unstint- 
ing consultation and laboratory services, and the Farm Department for services too numerous to list. We also wish to thank Mrs. Elaine Werboff of Storrs, CT, for her generous contribution of essential building materials.

\section{Endnotes}

${ }^{1}$ This study was funded by grants from the Faculty Research and Development Fund of the University of Michigan-Flint and from the Office of the Vice-President for Research, University of Michigan.

${ }^{2}$ All of the authors participated equally in the socialization program described in the present paper and are listed alphabetically.

${ }^{3}$ Department of Resource and Community Science, University of Michigan-Flint, Flint, MI 48503.

${ }^{4}$ Department of Psychology, Canisius College, Buffalo, NY 14209.

${ }^{5}$ Associate Professor, Departments of Resource and Community Science, Psychology, University of Michigan-Flint, Ilint, MI 48503. To whom reprint requests sbould be sent.

\section{References}

Albert, C, Goodmann, PA, and Klinghammer, E. n.d. Health care of wolves in captivity. In: Frank, H. ed. Man cind Woif: Advances, Iswes and Problems in Captive Wolf Research. The Hague: Junk Publishers. In press.

Frank, H. 1980. Evolution of canine information processing under conditions of natural and artificial selection. Zeitschr fur Tiertsychol. 53: 389-99.

Frank, H. and Frank, MG. 1982. Comparison of problem-solving performance in six-week-old wolves and dogs. Anim. Bebav. 30: 95-98.

-. 1983. Inhibition training in wolves and dogs. Behav. Proc. 8: 363-77

-. 1984. information processing in wolves and dogs. Acta ZoO. Fenin. 171: 225-28.

- 1985. Comparative manipulation-test performance in ten-week-old wolves (Canis lupus) and Alaskan Malamutes (Canis fomiliaris): A Piagetian interpretation. J. Comp. PSych. 9a)(3): 266-74.

Geist, V. 1978. Life Strategies, Human Evolution, Enuironmental Design: Touard a Biological Theory of Health. New York: Springer-Verlag.

Klinghammer, E and Goodmann, PA. n.d. Socialization and management of wolves in capivity In: Frank, H. ed. Man and Wolf: Advances, Issues and Problems in Captive Wolf Research. The Hague: Junk Publishers, In press.

Leyhausen, P. 1979. Cat Bebavior: The Predatory and Social Behavior of Domestic and Wila Cats. Tonkin, BA, trans., New York: Garland STMP. (Original work pubished 1956).

Scott, JP and Fuller, JL. 1965. Genetics and the Social Behavior of the Dog. Chicago: Univ. Chicago Press. Scott, JP, Shepard, JJ and Werboff, J. 1967. Inhibitory training of dogs: Effects of age at training in basenjis and shetland Sheepdogs. J. Psych. 6: $237-52$.

Tolman, EC and Honzik, CH. 1930. Introduction and removal of teward, and maze performance in rats. University of California Publications in Psychology. 4: 257-75. 